\title{
ARTIGO
}

\section{REPERCUSSÕES DO MOVIMENTO CTS NOS TRABALHOS DOS ENCONTROS NACIONAIS DE ENSINO DE QUÍMICA (2008-2016): CONTRIBUIÇÕES PARA A EDUCAÇÃO EM CIÊNCIAS/QUÍMICA ${ }^{1}$}

\author{
Mateus José dos Santos ${ }^{2}$ \\ Vinícius Catão
}

\begin{abstract}
RESUMO
O presente trabalho analisou a repercussão do movimento de contextualização Ciência, Tecnologia e Sociedade (CTS) nos anais dos Encontros Nacionais de Ensino de Química (ENEQs) entre 2008 e 2016. A escolha desse evento se fundamenta na importância que ele tem para a educação científica no Brasil, sobretudo por congregar estudantes e professores de Química que buscam debater os atuais desafios formativos. Em termos metodológicos, fez-se uma análise qualitativa exploratória dos trabalhos relacionados à abordagem CTS presentes nos anais dos ENEQs, para que em seguida estes pudessem ser analisados e interpretados à luz das teorias que contemplam as propostas de ensino pautadas nesta abordagem de ensino. $\mathrm{Na}$ sequência, foram apresentados os níveis de formação relacionados aos trabalhos selecionados, verificando assim a repercussão e abrangência da contextualização CTS desde os anos iniciais até o Ensino Superior. Concluiu-se que, apesar da notória escassez de trabalhos nos anos iniciais, o movimento CTS ganhou expressivo destaque nas últimas edições dos ENEQs, demonstrando contribuir para a formação de cidadãos críticos e reflexivos, com potencial para desenvolverem uma leitura mais apurada do mundo a sua volta.
\end{abstract}

Palavras-chave: Contextualização CTS. ENEQ. Ensino de Ciências/Química.

\section{INTRODUÇÃO}

Nos últimos anos, verifica-se um elevado número de trabalhos e debates que permeiam o enfoque Ciência, Tecnologia e Sociedade (CTS) em diferentes eventos de divulgação científica e popularização da Ciência, além dos congressos voltados à formação de professores. Os trabalhos publicados nesta área apresentam uma gama diversificada de abordagens, considerando a relevância de tal movimento (SANTOS; MORTIMER, 2002) e corroborando com a realidade na qual cada proposta foi desenvolvida e/ou implementada.

\footnotetext{
${ }^{1}$ Como citar este artigo: SANTOS, Mateus José dos; CATÃO, Vinícius. Repercussões do movimento CTS nos trabalhos dos encontros nacionais de ensino de química (2008-2016): contribuições para a educação em ciências/química ForScience: revista científica do IFMG, Formiga, v. 7, n. 1, e00598, jan./jun. 2019. DOI: 10.29069/forscience.2019v7n1.e598.
}

\footnotetext{
${ }^{2}$ Autor para correspondência: Mateus José dos Santos, e-mail: mateusard162@ gmail.com.
} 
O movimento CTS teve seu início na América Latina em meados do século XX, de forma a buscar romper com os laços da educação tradicional que ainda privilegia a memorização de conceitos/informações, trazendo para a sala de aula discussões sobre os problemas políticos e econômicos associados ao desenvolvimento tecnológico e à degradação ambiental (STRIEDER; KAWAMURA, 2017).

No Brasil, as discussões nesta área vêm tomando corpo desde a década de 1960, no entanto, muitas das pesquisas ainda se pautam no caráter crítico desse movimento, sem assumir um aspecto político presente nesse debate (ABREU; FERNANDES; MARTINS, 2013). Assim, muitas das discussões ainda requerem um aprofundamento maior, de forma que possam ir além das pesquisas, favorecendo transformações sociais nos ambientes em que tal movimento esteja inserido e não apenas um suporte para elaboração de atividades desconexas que acontecem esporadicamente, sem grandes vínculos com o desenvolvimento científicotecnológico da sociedade. Pinheiro, Silveira e Bazzo (2009) apontam que:

Ciência, Tecnologia e Sociedade - CTS corresponde ao estudo das inter-relações
existentes entre a ciência, a tecnologia e a sociedade, constituindo um campo de
trabalho que se volta tanto para a investigação acadêmica como para as políticas
públicas. Baseia-se em novas correntes de investigação em filosofia e sociologia da
ciência, podendo aparecer como forma de reivindicação da população para atingir
uma participação mais democrática nas decisões que envolvem o contexto
científico-tecnológico ao qual pertence (PINHEIRO; SILVEIRA; BAZZO, 2009,
p.2, grifo nosso).

Nesse sentido, atividades pautadas na abordagem CTS podem propiciar uma análise pormenorizada do ambiente que o indivíduo vive, de modo que o mesmo comece a questionar situações que acontecem ao seu redor. É importante que a escola, nesse momento, forneça subsídios necessários para que o estudante seja capaz de tomar consciência das situações problemas inerentes ao seu cotidiano e passe a se posicionar com mais criticidade.

Assim, faz-se necessário o desenvolvimento de atividades nas aulas que englobem os aspectos CTS, de modo a ampliar o caráter crítico-reflexivo do discente. Vale enfatizar ainda que um dos objetivos principais do movimento aludido é promover o letramento científico e tecnológico dos indivíduos, de forma a auxiliá-los na construção de conhecimentos e no desenvolvimento de competências, habilidades e valores imprescindíveis na busca por uma formação cidadã mais consciente e permeada por situações cotidianas, sobretudo aquelas relacionadas à Ciência e Tecnologia na Sociedade (SANTOS; MORTIMER, 2002). 
Geremias (2016), após analisar diversos pesquisadores e escolas que suscitaram o desenvolvimento das discussões associadas à perspectiva CTS, como a de Frankfurt e a de Edimburgo, sintetiza alguns princípios norteadores relacionados ao movimento, a saber:

I. A compreensão construtiva e o estudo da ciência e da tecnologia em seu contexto social, político e cultural; II. A valorização crítica do desenvolvimento científico e tecnológico; III. As formas democráticas de intervenção nas questões que envolvem a ciência e a tecnologia (GEREMIAS, 2016, p. 46).

Com base nesses princípios norteadores, verifica-se que esse movimento tende a trazer o estudante para o centro do processo educativo. Ainda, chama atenção para as mudanças que vem ocorrendo no mundo e favorece intercâmbios profícuos entre aspectos intrínsecos à sociedade e os conhecimentos escolares. Além da compreensão crítica, dos contextos individuais de cada sujeito e dos aspectos democráticos, a intervenção social é algo extremamente importante nesse processo. Logo, possibilitar que os estudantes entendam os diferentes espaços sociais, se fazendo presentes neles como cidadãos capazes de interferir nesses ambientes, é algo essencial ao se abordar questões CTS nos contextos escolares, podendo articular estratégias que fujam da relação arcaica de transmissão-recepção de informações, sem uma análise crítica e reflexiva das mesmas.

Outro aspecto importante de ser levado em consideração ao analisar a inserção do movimento CTS nas aulas seria as aproximações dessa perspectiva com as ideias freireanas (STRIEDER, 2012). Um desses pontos de convergência relaciona-se com o fim da cultura do silêncio, ou seja, que os estudantes assumam posturas ativas na sociedade. De acordo com Paulo Freire (1987):

\footnotetext{
A existência, porque humana, não pode ser muda, silenciosa, nem tampouco pode nutrir-se de falsas palavras, mas de palavras verdadeiras, com que os homens transformam o mundo. Existir, humanamente, é pronunciar o mundo, é modificá-lo. O mundo pronunciado, por sua vez, se volta problematizado aos sujeitos pronunciantes, a exigir deles novo pronunciar. Não é no silêncio que os homens se fazem, mas na palavra, no trabalho, na ação-reflexão (FREIRE, 1987, p. 78).
}

Embasados por uma leitura crítica de mundo, os estudantes têm a oportunidade de tornar os debates mais democráticos, saindo da relação de educação bancária, na qual apenas ouvia, mas não contribuía com as discussões, o que vai ao encontro das propostas de Paulo Freire. Além disso, vale ressaltar que as ideias trazidas pelo movimento CTS e as de Paulo Freire defendem uma formação de cidadãos mais críticos, que além de participarem das decisões de forma democrática e emancipadora, sejam capazes de tomar posições frente às demandas da sociedade. Ou seja, intervir conscientemente na resolução de situações 
problemas relativos ao espaço social e que se relacionam diretamente com a aplicação dos conhecimentos oriundos da Ciência e da Tecnologia.

\section{IMPORTÂNCIA ATUAL DO ENEQ PARA O ENSINO DE CIÊNCIAS/QUÍMICA}

Com o apoio da Sociedade Brasileira de Química (SBQ), o Encontro Nacional de Ensino de Química (ENEQ) é um dos maiores eventos nacionais de Educação em Química e congrega professores, pesquisadores e estudantes que buscam divulgar seus trabalhos, compartilhar experiências e estabelecer parcerias com outros profissionais e/ou instituições.

Em 2018 o evento celebrou a sua décima nona edição e foi sediado na Universidade Federal do Acre, em Rio Branco, pela primeira vez, com o objetivo de estreitar ainda mais os laços com os professores e pesquisadores da região Norte do país.

O Quadro 1 apresenta a relação dos ENEQs, com a instituição promotora e o número de trabalhos publicados nos anais do evento ao longo das edições analisadas neste artigo.

\begin{tabular}{|c|c|c|}
\hline ANO & INSTITUIÇÃO & $\begin{array}{c}\text { TOTAL DE } \\
\text { TRABALHOS }\end{array}$ \\
\hline 2008 & $\begin{array}{c}\text { Universidade Federal } \\
\text { do Paraná } \\
\text { (UFPR) }\end{array}$ & 462 \\
\hline 2010 & $\begin{array}{c}\text { Universidade Federal } \\
\text { de Brasília } \\
\text { (UnB) }\end{array}$ & 573 \\
\hline 2012 & $\begin{array}{c}\text { Universidade Federal } \\
\text { da Bahia } \\
\text { (UFBA) }\end{array}$ & 1400 \\
\hline 2014 & $\begin{array}{c}\text { Universidade Feral de } \\
\text { Ouro Preto } \\
\text { (UFOP) }\end{array}$ & 1602 \\
\hline 2016 & $\begin{array}{c}\text { Universidade Federal } \\
\text { de Santa Catarina } \\
\text { (UFSC) }\end{array}$ & \\
\hline
\end{tabular}

Quadro 1 - Levantamento dos trabalhos publicados nos anais do ENEQ (2008-2016) Fonte: ENEQ (2008, 2010, 2012, 2014, 2016).

Com base nos dados do Quadro 1, verifica-se um aumento no quantitativo de trabalhos publicados nos anais do evento ao longo dos últimos anos, demonstrando que a cada edição, o evento vem atingindo mais pessoas, socializando produções importantes da área de Ciências/Química e, assim, fomentar discussões que possibilitem traçar melhorias para o desenvolvimento desta área junto às Escolas e às Instituições de Ensino Superior (IES). 
Um ponto importante verificado no histórico do evento foi constatar a evolução das áreas temáticas, corroborando com a importância de manter e aprofundar o diálogo entre os participantes e as pesquisas que vem sendo realizadas. Assim, a cada edição os organizadores avaliaram as diretrizes do evento, de forma a torná-lo condizente com os debates que vem se consolidando no campo do Ensino de Ciências e de Química. O Quadro 2 apresenta as áreas temáticas das edições analisadas nesse trabalho.

\begin{tabular}{|c|c|}
\hline ANO & Áreas Temáticas \\
\hline 2008 & $\begin{array}{l}\text { 1. Currículo e Avaliação - CA } \\
\text { 2. Ensino e Aprendizagem - EA } \\
\text { 3. História e Filosofia da Ciência no Ensino - HC } \\
\text { 4. Ensino em Espaços Não-Formais - EF } \\
\text { 5. Experimentação no Ensino - EX } \\
\text { 6. Formação de Professores - FP } \\
\text { 7. Linguagem e Cognição - LC } \\
\text { 8. Materiais Didáticos - MD } \\
\text { 9. Tecnologia da Informação e Comunicação no Ensino - TIC } \\
\text { 10. Ensino e Cultura - EC }\end{array}$ \\
\hline 2010 & $\begin{array}{l}\text { 1. Currículo e Avaliação - CA } \\
\text { 2. Ensino e Aprendizagem - EAP } \\
\text { 3. História e Filosofia da Ciência no Ensino - HC } \\
\text { 4. Ensino em Espaços Não-Formais - EF } \\
\text { 5. Experimentação no Ensino - EX } \\
\text { 6. Formação de Professores - FP } \\
\text { 7. Linguagem e Cognição - LC } \\
\text { 8. Materiais Didáticos - MD } \\
\text { 9. Tecnologia da Informação e Comunicação no Ensino - TIC } \\
\text { 10. Ensino e Cultura - EC } \\
\text { 11. Ensino e Inclusão - EI } \\
\text { 12. Educação Ambiental - EA }\end{array}$ \\
\hline 2012 & $\begin{array}{l}\text { 1. Currículo e Avaliação - CA } \\
\text { 2. Ensino e Aprendizagem - EAP } \\
\text { 3. História e Filosofia da Ciência - HC } \\
\text { 4. Ensino em Espaços Não-Formais - EF } \\
\text { 5. Experimentação no Ensino - EX } \\
\text { 6. Formação de Professores - FP } \\
\text { 7. Linguagem e Cognição - LC } \\
\text { 8. Materiais Didáticos - MD }\end{array}$ \\
\hline
\end{tabular}




\begin{tabular}{|c|c|}
\hline & $\begin{array}{l}\text { 9. Tecnologia da Informação e Comunicação - TIC } \\
\text { 10. Ensino e Cultura - EC } \\
\text { 11. Ensino e Inclusão - EI } \\
\text { 12. Educação Ambiental - EA }\end{array}$ \\
\hline 2014 & $\begin{array}{l}\text { 1. Ensino e Aprendizagem - EAP } \\
\text { 2. Formação de Professores - FP } \\
\text { 3. Materiais Didáticos - MD } \\
\text { 4. Linguagem e Cognição - LC } \\
\text { 5. Experimentação no Ensino - EX } \\
\text { 6. História, Filosofia e Sociologia da Ciência - HFS } \\
\text { 7. Educação em espaços Não-Formais e divulgação científica - EFD } \\
\text { 8. Tecnologias da Informação e Comunicação - TIC } \\
\text { 9. Educação ambiental - EA } \\
\text { 10. Abordagem Ciência, Tecnologia e Sociedade - CTS } \\
\text { 11. Currículo e Avaliação - CA } \\
\text { 12. Inclusão e Políticas Educacionais - IPE }\end{array}$ \\
\hline 2016 & $\begin{array}{l}\text { 1. Ciência, Tecnologia e Sociedade } \\
\text { 2. Currículo e Avaliação } \\
\text { 3. Educação Ambiental } \\
\text { 4. Educação em Espaços Não-Formais e Divulgação Científica } \\
\text { 5. Ensino e Aprendizagem } \\
\text { 6. Experimentação no Ensino } \\
\text { 7. Formação de Professores } \\
\text { 8. História, Filosofia e Sociologia da Ciência } \\
\text { 9. Inclusão e Políticas Educacionais } \\
\text { 10. Linguagem e Cognição } \\
\text { 11. Materiais Didáticos } \\
\text { 12. Tecnologias da Informação e Comunicação }\end{array}$ \\
\hline
\end{tabular}

De acordo com os dados presentes no Quadro 2, constata-se a inserção de novas áreas temáticas ao longo das edições. Verifica-se, em negrito, que foi inserida nas edições de 2014 e 2016 uma área temática específica para trabalhos em diálogo com o movimento CTS. Nesse sentido, entende-se que o evento está atento às evoluções e tendências da área, demonstrando mais uma vez a sua importância para o cenário nacional. Além disso, cabe destacar que a abordagem CTS vem ganhando cada vez mais destaque, sendo discutida em diversos programas de pós-graduação e congressos de formação de professores. Isto aponta para a sua importância no âmbito da escola e demais espaços formativos, de maneira que os 
profissionais da educação possam construir estratégias de aprendizagem pautadas nesta perspectiva de ensino que tende a contribuir para a formação de cidadãos mais críticos e conscientes da sua importância no meio em que vivem.

\section{METODOLOGIA}

Para analisar os trabalhos do ENEQ de 2008-2016, foram feitos dois recortes distintos. Primeiramente, para as edições em que não havia uma área temática específica dos trabalhos que abordassem o aspecto CTS, buscou-se a sigla CTS em palavras-chaves e títulos dos trabalhos publicados. Após a edição de 2014, os trabalhos relacionados ao enfoque CTS ganharam uma área temática específica. Assim, para estas edições foram levados em consideração apenas os trabalhos relativos a esta nesta linha temática, visto que, eles deveriam apresentar diálogos mais profícuos com as discussões relacionadas à abordagem CTS. Dessa forma, optou-se pela pesquisa qualitativa exploratória, no intuito de entender de modo pormenorizado o corpus de análise e, posteriormente, realizar interpretações mais detalhadas da importância dos trabalhos que abordam tal temática.

Nessa perspectiva, a pesquisa qualitativa se pauta em teorias que fazem emergir um corpus a ser analisado, mas cabe aos pesquisadores a responsabilidade da construção dos fenômenos sociais, ou seja, das interpretações a partir do objeto de pesquisa a ser analisado (DAL-FARRA; LOPES, 2013). Logo, por meio dos dados, a teoria ancorada em questões vinculadas ao enfoque CTS favoreceu a análise dos trabalhos que indicavam a importância de tal abordagem no Ensino de Ciências/Química e de como as estratégias e propostas didáticas foram implementadas, de modo a corroborarem com tal perspectiva em suas práticas docentes.

Partindo desses pressupostos, o trabalho se estruturou nas seguintes etapas: (i) construção do corpus de análise - verificação e análise dos anais do evento entre as edições de 2008-2016; (ii) relação dos trabalhos aprovados com a abordagem CTS - análise do vínculo entre os trabalhos selecionados e a abordagem CTS; (iii) evolução da abordagem CTS ao longo das edições do evento - análise dos dados selecionados, por meio de gráficos e/ou tabelas, de modo a verificar a evolução dessa abordagem ao longo das edições do evento; e (iv) método indutivo - com base em Neves (1996), analisou indutivamente os dados, de forma a fazer associações com as discussões presentes atualmente sobre a abordagem pesquisada. Assim, neste último item buscou-se (co)relacionar as observações feitas sobre o corpus de análise e, a partir delas, estabelecer os diálogos realizados entre o que se pesquisa sobre a 
abordagem CTS e sua relação com a Educação Química e a Educação em Ciências na perspectiva do ENEQ.

\section{RESULTADOS E DISCUSSÃO}

Para uma melhor compreensão dos trabalhos relacionados ao enfoque CTS, analisouse a evolução deles entre os anos de 2008 e 2016. A Figura 1 mostra que aumentou significativamente o número de produções relacionadas ao movimento CTS. Nesse sentido, cabe destacar que desde 2008 aumentaram-se as propostas voltadas a abordar a interação entre Ciência, Tecnologia e Sociedade/Ambiente, chegando a 2016 com um aumento exponencial de trabalhos relacionados com esta abordagem.

Vale salientar que nas edições de 2014 e de 2016 foi considerada a área temática Ciência-Tecnologia-Sociedade, conforme apresentado no Quadro 2. Ou seja, a inserção de uma área temática específica possibilitou uma análise mais assertiva dessas publicações.

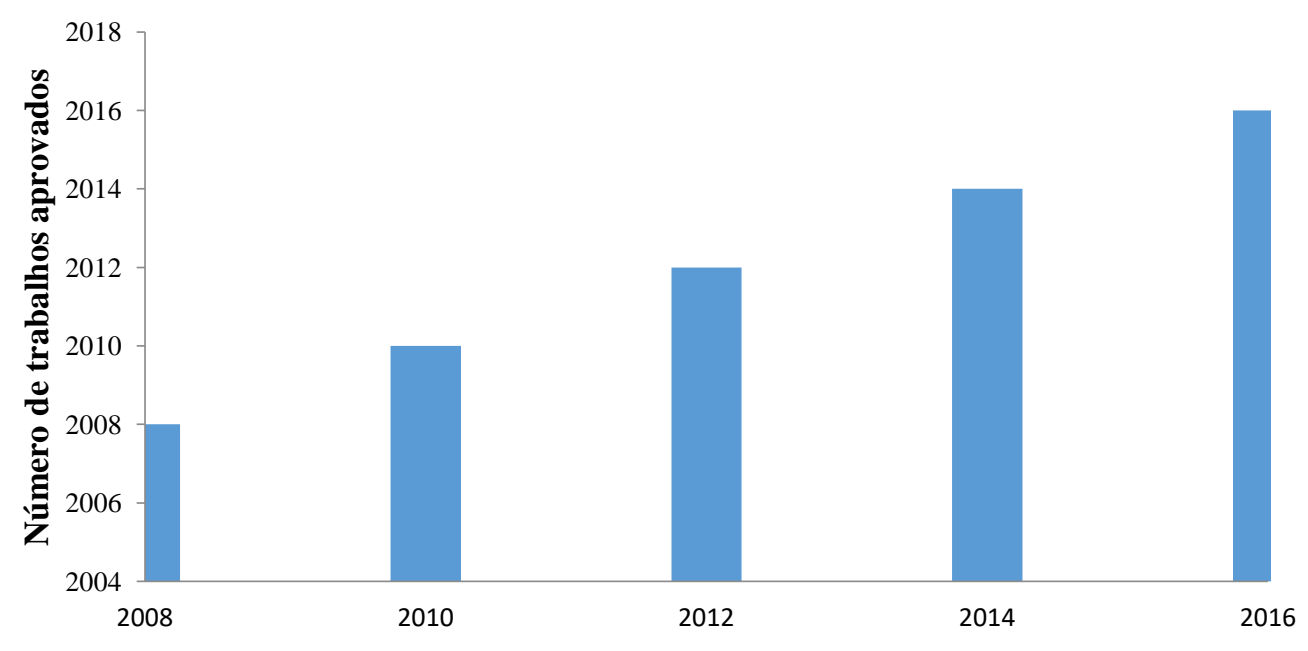

Edições do ENEQ

Figura 1 - Evolução dos anais pautados no enfoque CTS ao longo das edições do ENEQ Fonte: Autores (2018).

A Figura 2 apresenta uma relação percentual dos trabalhos com enfoque CTS e o número total daqueles publicados em cada uma das cinco edições analisadas. 


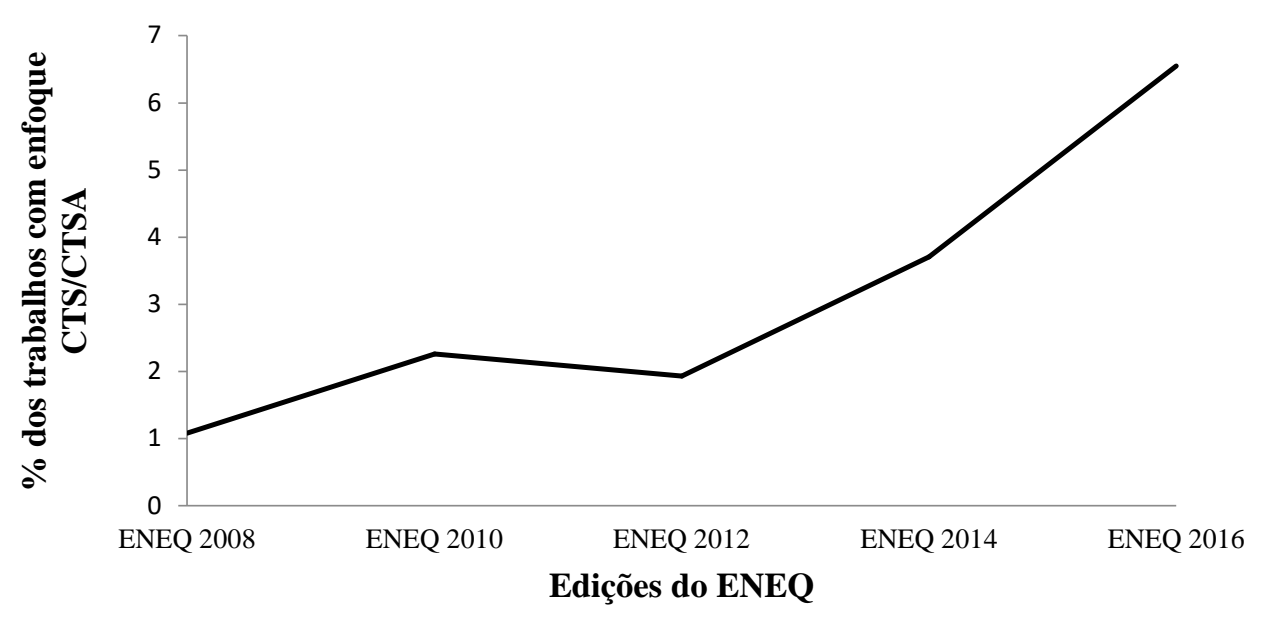

Figura 2 - Percentual de trabalhos com abordagem CTS em relação ao número total de trabalhos publicados Fonte: Autores (2018).

Na Figura 2, evidencia-se a evolução dos trabalhos ao longo dos anos e, por meio dessa análise, verifica-se que houve uma pequena queda durante a edição de 2012. É importante ressaltar que com a comemoração do Ano Internacional da Química (AIQ) em 2011, foi solicitado às Escolas e Universidades que trabalhassem esta temática junto aos seus estudantes, com o intuito de divulgar e popularizar a Ciência.

Com esta política de incentivo à popularização da Ciência, os trabalhos do ENEQ 2012 versaram, em sua maior parte, sobre as práticas sociocientíficas realizadas com o intuito de divulgação, popularização e alfabetização científica. Foi a partir deste evento que trabalhos na perspectiva CTS começaram a ser debatidos e incorporados em diferentes discussões relativas à contextualização no ensino de Ciências/Química, verificando um aumento no número de produções a partir das edições subsequentes do ENEQ.

Em 2012 sobressaíram-se discussões permeadas pela divulgação científica, de uma maneira geral, e isto pode ter sido um fator importante que justifica o pequeno decréscimo de trabalhos que dialogam com a abordagem CTS. Outro aspecto relevante da Figura 2 foi verificar que com a inserção da área temática em 2014, o número de trabalhos aumentou, triplicando em 2016. Constatou-se que os profissionais e estudantes da área de Ciências/Química estão começando a inserir em suas práticas propostas que contemplavam o movimento CTS, mesmo que ainda de maneira incipiente. No entanto, tal número tende a crescer, sobretudo pelas discussões que têm sido realizadas em programas de pós-graduação no que tange o movimento CTS e que o considera imprescindível na busca por uma formação cidadã mais democrática. Nesse sentido, Schnetzler e Santos (2008, p. 68) apontam que a 
perspectiva CTS “relaciona-se à solução de problemas da vida real que envolve aspectos sociais, tecnológicos, econômicos e políticos" enquanto outro "refere-se à compreensão da natureza da ciência e do seu papel na sociedade".

Outro aspecto importante a ser levado em conta é a necessidade de avaliar o nível de ensino em que tais trabalhos envolvendo a abordagem CTS foram implementados. A Figura 3 apresenta esta relação.

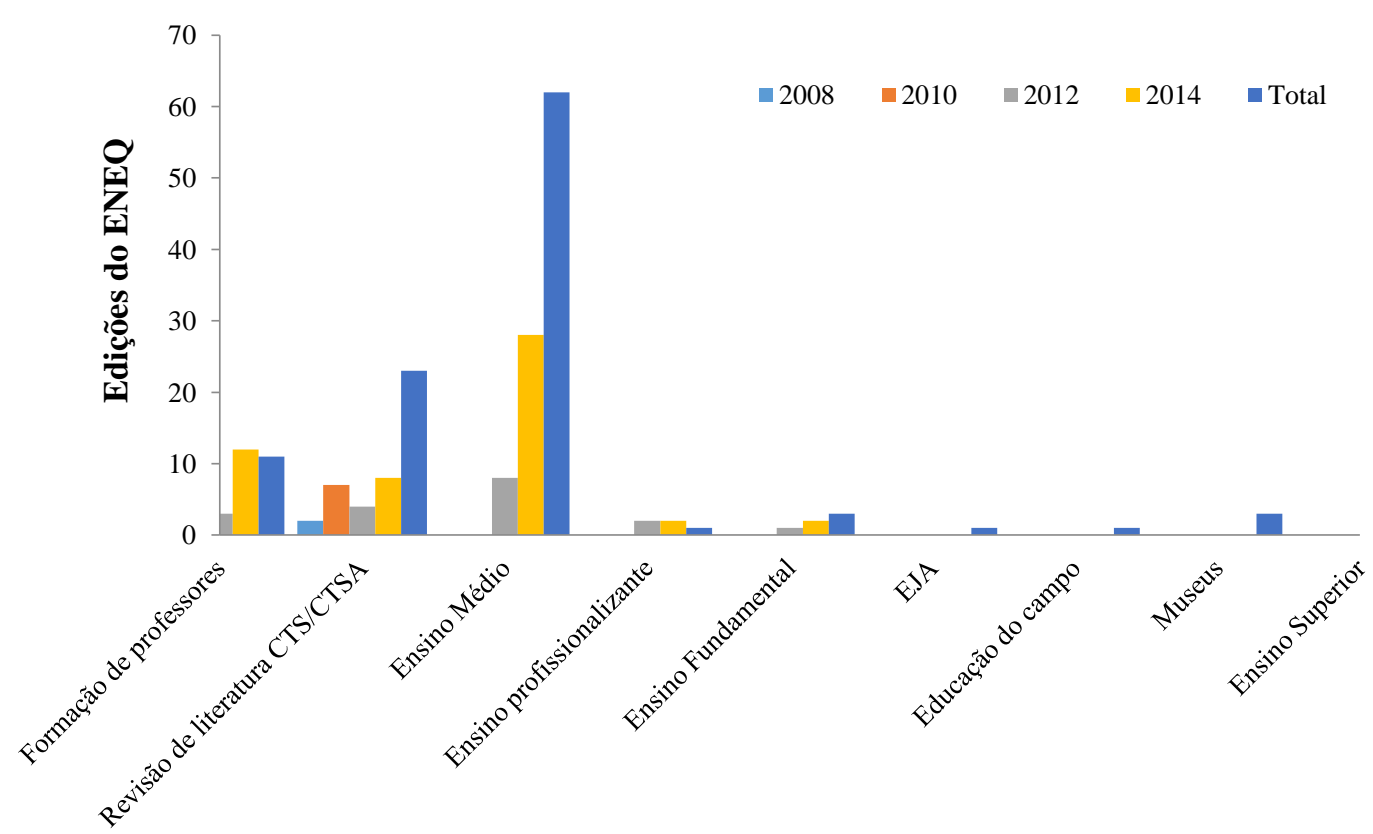

Categorias de implementação da abordagem CTS/CTSA

Figura 3 - Implementação da abordagem CTS a partir dos trabalhos presentes nos anais do ENEQ (2008-2016) Fonte: Autores (2018).

Com base nesta Figura, verifica-se que o foco principal dos trabalhos que corroboram com o movimento CTS está no Ensino Médio. Diversos deles apresentaram temas de cunho sociocientíficos inerentes à realidade dos estudantes participantes das atividades propostas. Além disso, destaca-se o número de trabalhos que se pautam na pesquisa qualitativa exploratória e/ou buscam analisar o movimento CTS em diferentes contextos, como nos livros didáticos, artigos publicados em revistas de grande circulação, trabalhos de congressos simpósios e encontros, dentre outros.

É importante salientar que esses trabalhos não apresentam propostas que ajudam os professores e estudantes a compreenderem o movimento CTS e a importância da implementação dessa abordagem junto aos estudantes da Educação Básica e do Ensino Superior. Isso corrobora com Abreu, Fernandes e Martins (2013), quando apontam para falta 
de pesquisas que assumam um caráter político em suas discussões e que desenvolvam esta abordagem nas aulas para que a partir daí se possam fazer análises mais detalhadas do caráter crítico e político desse movimento.

Além das investigações sobre o movimento CTS, há publicações que apresentam pesquisas que ajudam a compreender as concepções/percepções sobre essa abordagem entre os professores e estudantes, implementadas em diferentes contextos. As mesmas possuem um caráter importante, pois permitem analisar o que se sabe e o que deve ser realizado para desenvolver atividades em diálogo com o movimento CTS. Entretanto, as pesquisas concretizadas nesse sentido são realizadas em contextos específicos e nem sempre os sujeitos diretamente envolvidos em diferentes regiões apresentarão as mesmas concepções. Logo, trabalhos dessa natureza, além de uma análise diagnóstica, deveriam propor estratégias que ajudassem os sujeitos pesquisados a ressignificarem suas concepções/percepções sobre o movimento CTS, de modo a perceber a sua importância na busca pela formação de indivíduos com uma maior leitura crítica de mundo, constituindo um dos principais desafios para a implementação desta abordagem em diferentes níveis de ensino (FAGUNDES et al., 2009).

Por fim, verifica-se que o movimento CTS ainda não atingiu alguns espaços formativos de maneira efetiva. Com base na Figura 3, o Ensino Fundamental I e II, a Educação de Jovens e Adultos (EJA), o Ensino Profissionalizante e o Ensino Superior são níveis de ensino em que ainda carece de uma maior atenção quando se deseja implementar atividades que associam Ciência e Tecnologia à Sociedade/Ambiente. Este panorama pode acarretar sérios dilemas na Educação Básica, uma vez que, os estudantes chegam ao Ensino Médio sem uma leitura crítica e reflexiva de mundo, o que é elucidado pelo viés propedêutico da Escola e pelo modo como os conteúdos químicos são abordados nas aulas (BOUZON et al., 2018). Logo, é importante que no Ensino Fundamental os estudantes já comecem a construir noções pautadas em conhecimentos científicos e que percebam que há explicações para os inúmeros fatos e fenômenos existentes na natureza (BONFIM; GUIMARÃES, 2015). Dessa forma os estudantes poderão começar a construir seus próprios conhecimentos a partir de situações intrínsecas ao meio em que vivem de forma a desenvolver valores, atitudes e uma maior compreensão de mundo em uma perspectiva contextualizada e interdisciplinar.

Além do Ensino Fundamental I e II, faz-se necessário o desenvolvimento de atividades pautadas no movimento CTS em outras esferas da educação, como a EJA, o Ensino Profissional e o Ensino Superior. É indispensável que os sujeitos presentes nesses espaços compreendam a importância de se entender as relações da Ciência e da Tecnologia com a Sociedade, para começarem a articular o que se aprende na Escola com elementos de seu dia a 
dia na busca pelo desenvolvimento de um pensamento crítico de mundo e de uma argumentação mais consistente frente a situações presentes no contexto do discente. Acreditase que por meio dessas relações tais sujeitos se farão cidadãos ativos na comunidade em que vivem e passarão a assumir posições importantes diante das situações-problemas que surgem no dia a dia. Logo, é importante que os docentes que trabalham em tais ambientes não negligenciem tal movimento e passe a articular ações que possibilitem aos estudantes se fazerem presentes nos espaços educativos e serem multiplicadores de ideias que possibilitem contribuir para mudanças efetivas em suas realidades.

\section{CONSIDERAÇÕES FINAIS}

Com base nesse trabalho, destaca-se a importância do movimento CTS para a promoção de um caráter crítico-reflexivo nas aulas. Tal iniciativa possibilita o desenvolvimento de uma formação cidadã que pode favorecer ao estudante ser a peça fundamental do seu processo educativo e começar a se posicionar diante das situações problemas existentes em sua realidade. Tais características aproximam o movimento CTS-das propostas freireanas e propiciam o desenvolvimento de estratégias e ações que vão além da memorização de informações, conceitos e fórmulas desvinculadas da realidade.

Sobre o movimento CTS, é importante destacar que ele ainda está presente de forma incipiente entre os profissionais da área do Ensino de Ciências e de Química. Após a análise dos anais dos ENEQs (2008-2016), verificou-se que o encontro vem sofrendo ressignificações e já considera a abordagem CTS como uma das áreas temáticas do evento. Essa mudança possibilita que os participantes enviem trabalhos em consonância coma a perspectiva de tal movimento, o que não acontecia em edições anteriores à de 2014.

É importante considerar que por mais que esta área tenha ganhado destaque no ENEQ, são poucos os trabalhos que versam sobre práticas CTS em sala de aula e que abarque o Ensino Fundamental, a EJA e o Ensino Profissionalizante. Muitas pesquisas estão centradas na formação de professores, buscando resgatar suas concepções/percepções a respeito de tal movimento e na análise da abordagem CTS em diferentes contextos, tais como artigos, anais de eventos, revistas, textos de divulgação científica, dentre outros, e no Ensino Médio. Assim, as demais esferas da educação carecem de práticas pedagógicas que englobem o movimento CTS, contribuindo para a formação crítica dos estudantes desde os primeiros anos da Educação Básica até o Ensino Profissional. 
Por fim, a pesquisa realizada demonstra um cenário geral do que vem sendo divulgado em um importante evento nacional que acontece a cada dois anos em diferentes regiões do país e abarca professores da Educação Básica, verificando que o movimento CTS ainda não está articulado em todas as esferas da Educação.

Outro desafio encontrado a partir dessa análise é a falta de trabalhos no Ensino Superior, uma vez que muitos daqueles analisados restringem-se em apenas criticar a falta da abordagem CTS na formação inicial de profissionais em diferentes áreas. Nesse sentido, o Ensino de Química nos cursos de formação inicial acabam ficando restritos à mera transmissão de conteúdos e apresentam diálogos descontextualizados e fragmentados com a realidade profissional. Por mais que os estudantes cheguem com uma análise mais crítica e reflexiva ao nível superior, os professores tendem a não considerar esta maturidade dos estudantes em suas aulas. Na maior parte dos casos, os estudantes são levados a assumirem uma postura passiva nas aulas, sem estabelecerem interações dialógicas e, por consequência, tendo podado o desenvolvimento da capacidade argumentativa deles. Logo, urge a necessidade de uma formação mais democrática, ativa e empreendedora no Ensino Superior, que incorpore as práticas CTS e contribua ainda mais para o desenvolvimento de um profissional com uma postura crítica e reflexiva frente à sociedade e seus muitos desafios.

\title{
REPERCUSSIONS OF THE SCIENCE-TECHNOLOGY-SOCIETY APPROACH IN ANNALS OF THE BRAZILIAN CONFERENCE ON CHEMISTRY EDUCATION (2008-2016): CONTRIBUTIONS TO SCIENCE AND CHEMISTRY EDUCATION
}

\begin{abstract}
This paper analyzed the repercussion of the Science-Technology-Society (STS) approach in the annals of Brazilian Conference on Chemistry Education (BCCE) between the years 2008 and 2016. This conference was selected considering its importance for scientific education. Besides, it gathers students and chemistry teachers that seek to discuss the current training challenges in Science Education. In methodological terms, it was done a qualitative exploratory analysis of the papers related to the STS approach of the ENEQs annals. These papers were analyzed and interpreted in the light of the theories of teaching proposals. Then, it was presented the education levels related to the selected papers, aiming to verify the repercussion and scope of the STS approach from early years of education until its higher levels. The conclusion is that, despite the shortage of papers in the early years, the STS approach grown up in recent editions of the BCCE. This grown contributes to the development of critical and reflexive citizens, with potential to improve a more accurate and deeper reading of the social environment and scientific knowledge.
\end{abstract}

Keywords: Science-Technology-Society approach. BCCE. Science/Chemistry Education. 


\section{REFERÊNCIAS}

ABREU, Teo Bueno de, FERNANDES, João Paulo; MARTINS, Isabel. Levantamento sobre a produção CTS no Brasil no período de 1980-2008 no campo de Ensino de Ciências.

Alexandria: Revista de Educação em Ciência e Tecnologia, Florianópolis, v. 6, n. 2, p. 332, 2013.

BONFIM, Hanslivian Correia Cruz; GUIMARAES, Orliney Maciel. A abordagem CTS no Ensino de Ciências nos anos iniciais do Ensino Fundamental: um caminho para a cidadania. In: EDUCERE - XII Congresso Nacional de Educação, 2015, Curitiba. Anais... Curitiba, 2015. p. 3727-3739.

BOUZON, Júlia D.; BRANDÃO, Juliana B.; SANTOS, Taís C. dos; CRHISPINO, Álvaro. O Ensino de Química no Ensino CTS Brasileiro: uma revisão bibliográfica de publicações em periódicos. Química Nova na Escola, São Paulo, v. 40, n. 3, p. 214-225, 2018.

DAL-FARRA, Rossano André; LOPES, Paulo Tadeu Campos. Métodos mistos de pesquisa em educação: pressupostos teóricos. Nuances: Estudos sobre Educação, Presidente Prudente, v. 24, n. 3, p. 67-80, 2013.

ENCONTRO NACIONAL DE ENSINO DE QUÍMICA (ENEQ), Curitiba-PR, Anais..., 2008. Disponível em: http://www.quimica.ufpr.br/eduquim/eneq2008/. Acessado em: 30 junho de 2018.

ENCONTRO NACIONAL DE ENSINO DE QUÍMICA (ENEQ), Brasíla-DF, Anais..., 2010. Disponível em: http://www.sbq.org.br/eneq/xv/editorial.htm. Acessado em: 30 junho de 2018.

ENCONTRO NACIONAL DE ENSINO DE QUÍMICA (ENEQ), Salvador-BA, Anais..., 2012. Disponível em: http://www.eneq2012.qui.ufba.br. Acessado em: 30 junho de 2018.

ENCONTRO NACIONAL DE ENSINO DE QUÍMICA (ENEQ), Ouro Preto-MG, Anais..., 2014. Disponível em: www.eneq2014.ufop.br. Acessado em: 30 junho de 2018.

ENCONTRO NACIONAL DE ENSINO DE QUÍMICA (ENEQ), Florianópolis-SC, Anais..., 2016. Disponível em: www.eneq2016.ufsc.br. Acessado em: 30 junho de 2018.

FAGUNDES, Suzana Margarete Kurzmann; PICCINI, Ingrid Pereira; LAMARQUE, Tatiele; TERRAZZAN, Eduardo Adolfo. Produções em educação em ciências sob a perspectiva CTS. In: ENPEC - ENCONTRO NACIONAL DE PESQUISA EM EDUCAÇÃO EM CIÊNCIAS E I CIEC - CONGRESO IBEROAMERICANO DE INVESTIGACIÓN EN ENSEÑANZA DE LAS CIENCIAS, Florianópolis. Anais... Florianópolis, 2009, p. 1-12.

FREIRE, Paulo. Pedagogia do oprimido. 17. ed. Rio de Janeiro: Paz e Terra, 1987. 
GEREMIAS, Bethânia Medeiros. Produção de sentidos sobre tecnologia no grupo observatório da educação-ciências: discursos e problematizações. 2016. 303 f. Tese (Doutorado em Educação Científica e Tecnológica) - Universidade Federal de Santa Catarina, Florianópolis, 2016.

NEVES, José Luis. Pesquisa qualitativa: características, usos e possibilidades. Cadernos de Pesquisas em Administração, São Paulo, v. 1, n. 3, p. 1-5, 1996.

PINHEIRO, Nilcéia Aparecida Maciel; SILVEIRA, Rosemari Monteiro Castilho Foggiatto; BAZZO, Walter Antonio. O contexto científico tecnológico e social acerca de uma abordagem crítico-reflexiva: perspectiva e enfoque. Revista Iberoamericana de Educación, Madrid, v.1, n. 49, p. 1-14, 2009.

SANTOS, Wildson Luiz Pereira dos; MORTIMER, Eduardo Fleury. Uma análise de pressupostos teóricos da abordagem C-T-S (Ciência-Tecnologia-Sociedade) no contexto da educação brasileira. Ensaio: Pesquisa em Educação em Ciências, Belo Horizonte, v. 2, n. 2, p. 1-23, 2002.

SCHNETZLER, Roseli Pacheco; SANTOS, Wildson Luiz Pereira dos. Educação em química: compromisso com a cidadania. Ijuí: Unijuí, 2008.

STRIEDER, Roseline Beatriz. Abordagens CTS na educação científica no Brasil: sentidos e perspectivas. 2012. 283 f. Tese (Doutorado em Ciências) - Universidade de São Paulo, São Paulo, 2012.

STRIEDER, Roseline Beatriz; KAWAMURA, Maria Regina Dubeux. Educação CTS: parâmetros e propósitos brasileiros Alexandria: Revista de Educação em Ciência e Tecnologia, Florianópolis, v. 10, n. 1, p. 27-56, 2017.

\section{DADOS DOS AUTORES}

\section{Mateus José dos Santos}

E-mail: mateusard162@gmail.com

Currículo Lattes: http://lattes.cnpq.br/3159016812184117

Mestrando em Educação pela Universidade Federal de Viçosa (UFV), pós-graduando em Docência na Educação Básica pelo Instituto Federal de Minas Gerais (IFMG). Especialista em Ensino de Química pela Universidade Cândido Mendes (UCAM) e Licenciado em Química pela UFV. Participou do programa Ciência sem Fronteiras, fomentado pela CAPES, realizando suas atividades no Collège communautaire du Nouveau-Brunswick - Campus Bathurst e no Cégep de Sherbrooke, ambos no Canadá. Atualmente é professor de Ciências/Química do Colégio Educar de Ervália.

\section{Vinícius Catão}

E-mail: vcasouza@gmail.com

Currículo Lattes: http://lattes.cnpq.br/2185333448062588 
Doutorado e Mestrado em Educação (Ensino de Ciências), pela Faculdade de Educação da Universidade Federal de Minas Gerais, especialização em Educação Inclusiva, pela Escola de Governo da Fundação João Pinheiro e Licenciatura em Química pela Universidade Federal de Minas Gerais (UFMG). Atualmente é professor Adjunto no Departamento de Química da Universidade Federal de Viçosa (UFV). Possui experiências profissionais com temas relacionados ao ensino de Ciências/Química, espaços não formais de educação, formação inicial e continuada de professores, inclusão de surdos e diversidade na Escola, tendo feito trabalhos voltadas à educação socioambiental, educação e cidadania, metodologias de ensino e de pesquisa, história da Ciência aplicada ao ensino, alfabetização científica e processos aprendizagem na perspectiva inclusiva. 